\title{
IVERMECTINA NO TRATAMENTO DA COVID 19
}

\author{
IVERMECTIN IN THE TREATMENT OF COVID I9
}

\author{
Dalila Lage Pinto Morais 1 \\ Guilherme Henrique Miranda Sousa ${ }^{2}$ \\ Iza Natalia Silva Fonseca ${ }^{3}$ \\ Kellyane de Sousa Miranda \\ Mariana Matos Oliveira Cunha ${ }^{5}$ \\ Wanderson Ferreira Horácio ${ }^{6}$ \\ William Argolo Saliba ${ }^{7}$
}

RESUMO: No final de 2019 foi divulgado o surgimento de um novo coronavírus, chamado de SARS-CoV-2, o qual é responsável pela a pandemia que foi decretada em março de 2020 pela Organização Mundial de Saúde (OMS). Desse modo, houve a busca de uma molécula, já existente no mercado, que pudesse ser uma alternativa de tratamento ou até a cura para o vírus. Dessa maneira, as pesquisas clínicas buscam compreender o uso de fármacos como antivirais, antiparasitários, anti-maláricos e, nesse contexto, a ivermectina, passou a ser o foco de diversos debates e dividiu opiniões entre os cientistas e os profissionais de saúde. Sendo assim, este estudo tem como objetivo realizar uma pesquisa de caráter bibliográfico no intuito de compreender como esse medicamento age no combate ao vírus SARS-CoV-2, ressaltando a importância destes estudos como uma forma de compreensão da pandemia que se estabeleceu em 2020.

Palavras-chave: Coronavírus. Ivermectina. Pandemia.Fármacos.Tratamento.

ABSTRACT: In late 2019, the emergence of a new coronavirus, called SARS-CoV-2, was announced, which is responsible for a pandemic that was decreed in March 2020 by the

\footnotetext{
'Discente do curso de Bacharel em Farmácia da Faculdade Única de Ipatinga (FUNIP). E-mail: dalilamorais@yahoo.com.br.

${ }_{2}^{2}$ Discente do curso de Bacharel em Farmácia da Faculdade Única de Ipatinga (FUNIP). E-mail: guilhermetiagosegios689@hotmail.com.

3Discente do curso de Bacharel em Farmácia da Faculdade Única de Ipatinga (FUNIP). E-mail: izafonsecazoiı@hotmail.com.

4Discente do curso de Bacharel em Farmácia da Faculdade Única de Ipatinga (FUNIP). E-mail: kellyanesousamiranda456@hotmail.com.

5Discente do curso de Bacharel em Farmácia da Faculdade Única de Ipatinga (FUNIP). E-mail: marimatos21.m@gmail.com .

${ }^{6}$ Discente do curso de Bacharel em Farmácia da Faculdade Única de Ipatinga (FUNIP). E-mail: wandersonfh.michel@gmail.com .

7Orientador. Docente da Faculdade Única de Ipatinga (FUNIP). E-mail: wasaliba@gmail.com.
} 
World Health Organization (WHO). Thus, there was a search for a molecule, already on the market, that could be an alternative treatment or even a cure for the virus. Thus, clinical research seeks to understand the use of drugs such as antivirals, antiparasitic, antimalarials and, in this context, ivermectin, became the focus of several debates and divided opinions between scientists and health professionals. Therefore, this study aims to conduct a bibliographic research in order to understand how this drug acts to combat the SARS-CoV-2 virus, emphasizing the importance of these studies as a way of understanding the pandemic that changes in 2020.

Keywords: Coronavirus. Ivermectin. Pandemic. Drugs.Treatment.

\section{INTRODUÇÃO}

No final do ano de 2019, a Organização Mundial da Saúde (OMS) foi comunicada pelas autoridades chinesas, acerca de diversos casos de pneumonia com causa desconhecida na cidade de Wuhan, que é província de Hubei, na República da China. Perante tal situação,os profissionais de saúde e pesquisadores do país buscavam entender o que estaria causando a doença,comunicou-seao mundo, em janeiro, que foi identificado e caracterizado o agente etiológico responsável pelo surto de pneumonia, o qual se tratava de uma nova espécie de coronavírus, denominado como Sars-CoV-2 (OPS, 2020).

No dia 20 de janeiro a OMS divulga então seu primeiro Relatório Situacional, este documento trouxe atualizações $\mathrm{e}$ informações sobre o agravamento da situação epidemiológica das regiões afetadas, posteriormente, a organização declarava que o novo coronavírus passa a ser considerado como uma Emergência de Saúde Pública de Importância Internacional. Devido então a sua grande evolução no que se refere ao número de contaminados a OMS passa em il de março de 2020, a caracterizá-lo como sendo uma pandemia (OPS, 2020).

Nesse contexto,houve um grande número de mortos e contaminado pela expansão da pandemia em decorrência do vírus SARSCov-2, no entanto, o conhecimento sobre uma terapia farmacológica que seja eficaz para a prevenção ou a cura dos pacientes infectados pelo COVID-i9 se manteve limitado. Entretanto, há varias estudos em andamento que buscam avaliar diversos fármacos como forma de controle e combate, sendo incluso neste contexto os estudos clínicos com novos e antigos medicamentos que já estavam em uso para o tratamento de outras doenças (ZHANG; LIU, 2020). 
Atualmente, existem pesquisas clínicas que buscamcompreender o uso de fármacos como antivirais, antimaláricos, anti-inflamatórios, imunomoduladorescomo meios de controle e combate do vírus responsável pela pandemia.Neste contexto, encontra-se as pesquisas relacionadas ao uso da Ivermectina, medicamento este que funciona como um agente antiparasitário e anti-helmíntico de amplo espectro de atividade (DUARTE et al., 2020).

Hoje este medicamento é utilizado na medicina veterinária como uma indicação de auxilio no tratamento de parasitoses, sendo também de uso humano na terapêutica de estrogiloidíase e oncocercose. Muito embora a ivermectina seja um fármaco que está no mercado há um período considerável, vem sendo estudado seu uso no tratamento de outras patologias. No que se refere ao estudo da ação da ivermectina sobre o SARS-CoV-2, a Organização Pan-Americana da Saúde (OPAS), afirma que foi bem sucedido o combate do vírus SARS-CoV-2 realizados in vitro no tratamento das células infectadas experimentalmente (DUARTE et al., 2020).

Neste sentido, este estudo tem como objetivo realizar uma pesquisa de caráter bibliográfico com intuito de compreender como a ivermectina age no combate ao vírus SARS-CoV-2. Vale ressaltar a importância deste estudo como uma forma de compreensão do atual cenário em que se encontra o mundo, bem como um mecanismo de interdisciplinaridade com diversas matérias estudas ao logo dos períodos do curso de Bacharel em Farmácia.

\section{METODOLOGIA}

A metodologia que será empregada se baseia em uma revisão bibliográfica de artigos científicos.Portanto, como o objetivo deste trabalho éanálise do uso da ivermectina no tratamento do covid-ı. Nesse ínterim,visando tal aprofundamento, sendo realizada pesquisas em periódicos, plataforma digitais como os sites do Ministério da saúde, ANVISA,OPAS, Biblioteca Virtual em Saúde-Scielo e PubMed. Como critérios de seleção (inclusão e exclusão), os documentos que não eram considerados oficiais foram excluídos. 


\section{COVID-19}

O coronavírus faz parte de uma grande família de vírus que são comuns em diversas espécies de animais, comogatos e morcegos. No entanto, é raro que este tipo de vírus infecte animais, maspode infectar humanos de diferentes formas e níveis de gravidade, como o SARS-CoV,que provoca infecções graves (TESINI, 2020).

O SARS-CoV-2, nome do vírus que causa a doença denominada COVID-i9 é responsável pela atual pandemia. Este vírus apresenta um espectro clínico que varia desde infecções assintomáticas a quadros graves,segundo a OMS, a maioria (cerca de 80\%) dos pacientes com COVID-I9 pode vim a ser assintomáticos ou oligossintomáticos, e a minoria (20\%) necessita de atendimento hospitalar, isto por apresentar dificuldades respiratória, deste em torno de $5 \%$ pode vim a precisar de suporte ventilatório (BRASIL, 2020).

Segundo o Ministério da Saúde os sintomas do COVID-i9 variam desde moderados a graves, podendo levar a morte. Sendo caracterizado por dois sintomas no mínimo, os quais pode ser: sensação febril ou febre, juntamente com tosse ou dor de garganta, coriza, dificuldade respiratória o que pode aparecer entre 2 a 14 dias após está contaminado com o COVID-ı9. Além disso, algumas pessoas infectadas podem não apresentar sintomas, mas podem transmitir o vírus (BRASIL, 2020).

O novo coronavírus é transmitido através de uma pessoa doente para outra por meio da dispersão pelo ar de gotículas contaminadas da boca ou do nariz, e estas gotículas podem se espalhar pelo ambiente e se depositar nas superfícies de objetos. De acordo com a Agência Nacional de Vigilância Sanitária (ANVISA) o diagnóstico deve ser realizado por meio de testes laboratoriais (ANVISA, 2020).

\section{IVERMECTINA}

A ivermectina, de fórmula molecular $\mathrm{C}_{48} \mathrm{H}_{74} \mathrm{O}_{\mathrm{I} 4}$ (Fig. I), é um anti-helmíntico que causa paralisia tônica da musculatura dos vermes, sendo, por isso, indicado no tratamento de infecções causadas por: Estrongiloidíase intestinal, Oncocercose, Filariose, Ascaridíase, Escabiose e Pediculose (ANVISA, 2020 
Figura $\mathrm{I}$-Estrutura da Ivermectina

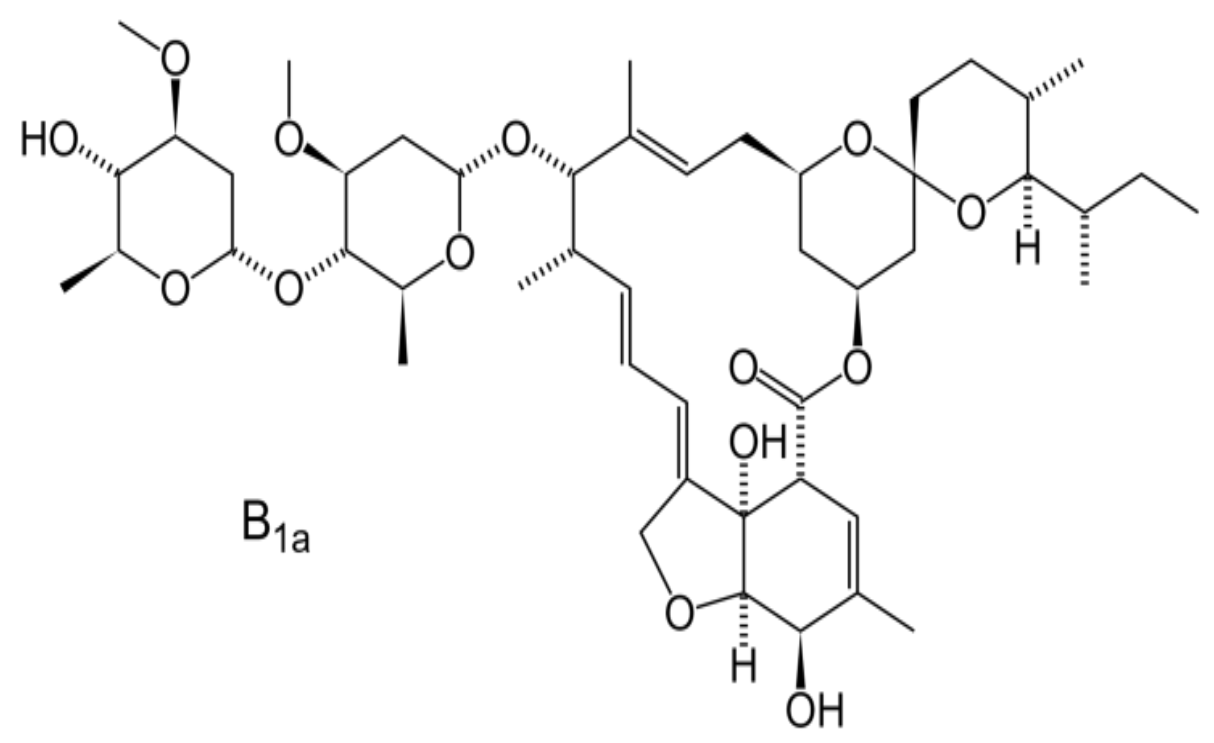

Fonte: CALY,et al.,2020.

O mecanismo de ação ocorre através da ligação do fármaco aos canais de cloro

mediados por glutamato, que são específicos de células musculares e nervosas de invertebrados. Quando ligada, a droga induz a abertura do canal e consequente aumento da permeabilidade da membrana celular aos íons cloreto, gerando hiperpolarização celular e finalmente causando a paralisia e morte do parasita. Devido às semelhanças estruturais, a Ivermectina pode também interagir com canais de cloro mediados por outros neurotransmissores como ácido gama-aminobutírico (GABA) (ANVISA, 2020).

A ivermectina é um agente antiparasitário de amplo espectro que demonstra atividade antiviral contra uma ampla gama de vírus in vitro. Originalmente identificado como um inibidor da interação entre a proteína integrase (IN) do vírus da imunodeficiência humana-I (HIV-I) e o heterodímeroimportina (IMP) $\alpha / \beta_{\text {I responsável }}$ pela importação nuclear de IN, a ivermectina tem desde então foi confirmado que inibe a importação nuclear de IN e a replicação do HIV-I(CALY et al.,2020). 


\section{IVERMECTINA NO TRATAMENTO CONTRA O COVID-I9}

Não há um tratamento específico que seja realmente eficaz para a COVID-ıg até a presente referência bibliográfica. Segundo as recomendações de várias organizações de saúde, como a Organização Mundial de Saúde (OMS), a Organização Pan-Americana de

Saúde (OPAS), a National Institutesof Health (NIH), Center for Disease Control and Prevention (CDC) e National Health Service (NHS) , o tratamento é apenas de suporte, já que não há um fármaco desenvolvido especificamente para esta doença (TELESSAÚDERS-UFRGS, 2020).

Sendo assim, o tratamento farmacológico oferecido para a COVID-I9 como "offlabel”, ou seja, é aquele que a indicação do profissional da saúde é diferente do que consta na bula. Dessa forma, os resultados clínicos destes tratamentos ainda são preliminares e não oferecem informações conclusivas (ANS, 2020).

A comprovação do benefício da Ivermectina nos pacientes portadores de COVIDI9 ainda é inicial e o uso não deve ser recomendado até que sejam aprovados os resultados dos ensaios clínicos que estão em andamento. Uma vez concluídos, os dados poderão ser avaliados para concluir sobre eficácia e segurança deste tratamento contra o vírus (BRASIL, 2020).

A relevância clínica farmacológica dos achados in vitro ou in vivo foi incluída como forma de achar a melhor terapêutica para a pandemia causada pelo COVID-19. A resposta farmacodinâmica é geralmente obtida garantindo-se uma duração adequada de exposição acima da concentração terapêutica mínima no local de ação(BRAY et al., 2020).

Segundo a pesquisa feita por Caly et al. (2020):

A ação antiviral proposta pela ivermectina no coronavírus relaciona-se a ligação do heterodímero $\alpha / \beta_{\mathrm{I}}$ da importina $\left(\mathrm{IMP} \alpha / \beta_{\mathrm{I}}\right)$ com a proteína de carga do coronavírus no citoplasma, desse modo heterodímero a transloca através do complexo de poros nucleares (NPC) para o núcleo onde o complexo se desintegra e a carga viral pode reduzir a resposta antiviral da célula hospedeira, levando a uma infecção avançada. A ivermectina se liga e desestabiliza o heterodímero Imp $\alpha / \beta \mathrm{I}$, impedindo assim a ligação de $\operatorname{Imp} \alpha / \beta_{\mathrm{I}}$ à proteína viral inferior $\mathrm{e}$ impedindo que ela entre no núcleo" (Fig. 2). Assim, esses indícios resultam provavelmente em inibição reduzida das respostas antivirais, levando a uma resposta antiviral normal e mais eficiente. (CALY et al.,2020) 
Figura 2. Proposta de ação antiviral exercida pela ivermectina no coronavírus

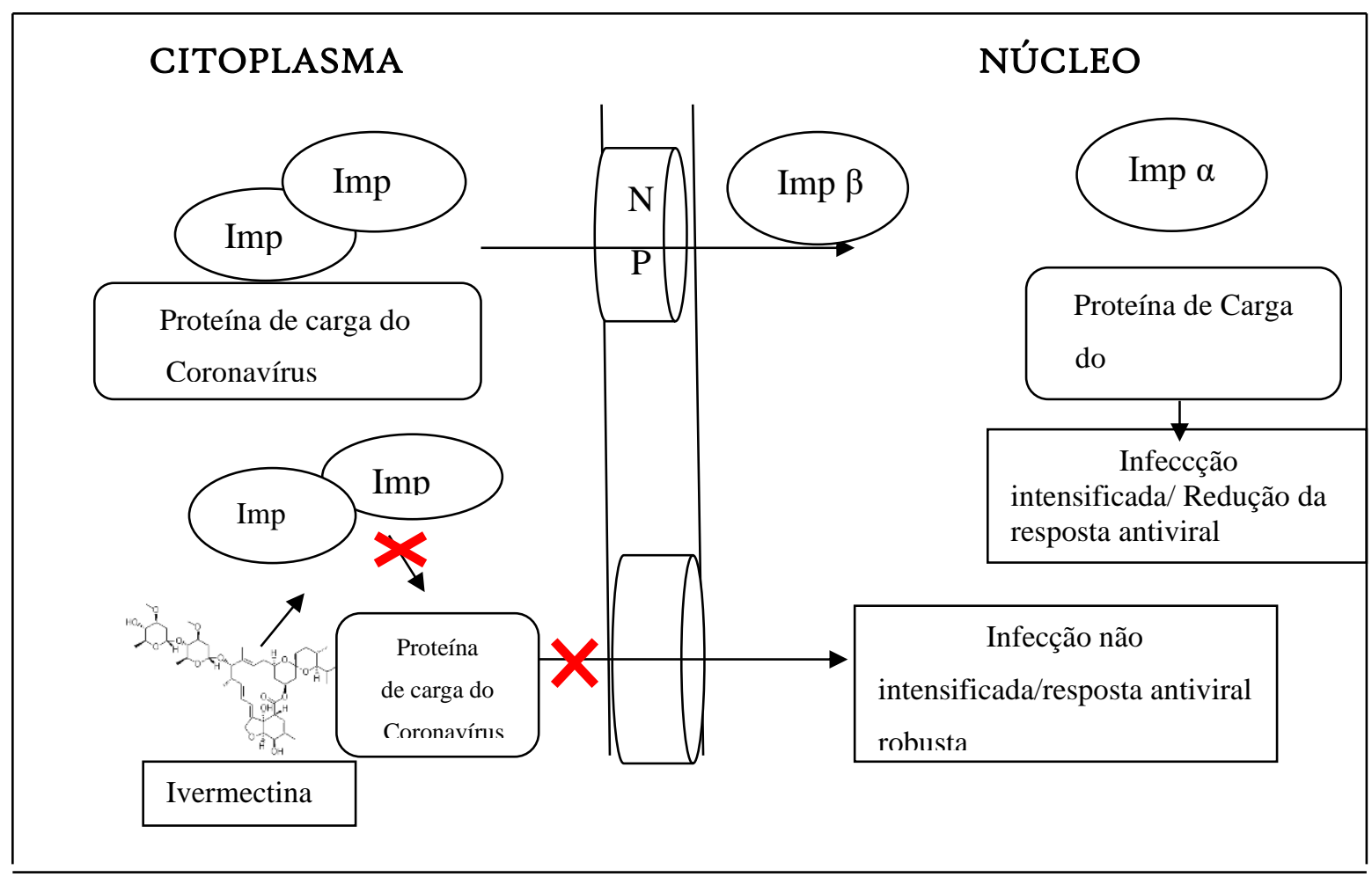

Fonte: ALBERT EINSTEIN, 2020. (modificado)

A infecção de células com SARS-CoV-2 isolado feita por Caly et al. (2020) para testar a atividade antiviral da ivermectina no combate ao coronavírus demonstrou em $48 \mathrm{~h}$, uma redução de aproximadamente cinco mil vezes do RNA viral em amostras tratadas com ivermectina em comparação com as amostras de controle, o que indicou que o tratamento com esse medicamento resultou na perda efetiva de todo o material viral nesse tempo. Nesse estudo não foi observado toxicidade.

A ivermectina lactona macrocíclica de amplo espectro inibiu a replicação do SARS$\mathrm{CoV}-2$ in vitro. No entanto, esta atividade in vitro ocorreu em concentrações muito mais altas do que as concentrações muito baixas eficazes contra muitas espécies de nematóides. Logo, as doses mais altas do que as usuais podem causar uma toxicidade desconhecida ao ser humano (BRAY et al., 2020). 
Segundo Barifouse e Lemos (2020), as buscas sobre a Ivermectina aumentaram, e em algumas farmácias o medicamento ficou em falta. Com isso as fábricas aumentaram a produção visando ao atendimento da demanda.

$\mathrm{O}$ interesse repentino pelo medicamento se deu por vários fatores, um deles foi o estudo colaborativo liderado pelo Biomedicine Discovery Institute (BDI) da MonashUniversity, o qual relatou que a Ivermectina já havia demostrado uma atividade antiviral in vitro de amplo espectro, sendo um inibidor do SARS-CoV-2 capaz de reduzir em 50oo vezes no RNA viral em 48h (CALY et al., 2020).

O aumento da demanda pelo uso off-label da Ivermectina no combate à COVID-I9 gerou uma preocupação pela Anvisa (Agência Nacional de Vigilância Sanitária), que criou normativos que passaram a exigir das drogarias receitas em duas vias para venda do vermífugo. No entanto, no início de setembro de 2020 a Anvisa emitiu uma nota liberando a venda do medicamento com uma via da receita. Estes fatores ignoram um fato importantíssimo, de que, até então, ainda não há a comprovação cientifica que a Ivermectina (ou algum outro medicamento) venha a prevenir ou curar a COVID-I9 (ASCOM/ANVISA, 2020).

\section{CONSIDERAÇÕES FINAIS}

Embasada nesta revisão bibliográfica pode-se concluir que atualmente já estão em curso estudos clínicos sobre o combate ao COVID-19, que utilizam fármacos já conhecidos e com efeitos farmacológicos estudados no organismo humano.

Nesse contexto, os estudos in vitro demonstraram a efetividade da ivermectina no combate ao SARS-CoV-2. Todavia, a dose utilizada para obter resultado é elevada, em relação à dosagem utilizada usualmente para outras condições patológicas, o que pode ocasionar toxicidade ao organismo humano.

Logo, observa-se a necessidade de mais os estudos clínicos no que tange ao uso da ivermectina no tratamento contra oSARS-CoV-2, a fim de definir a relação existente entre o benefício, as reações adversas e a dosagem utilizada na terapêutica dessa enfermidade. Entende-se, portanto, que é relevante o bom senso clínico da equipe médica e multidisciplinar no que concerne ao tratamento ofertados às pessoas infectadas pelo 
COVID-19, além disso esses profissionais devem manter como focoo suporte à vida do paciente.

\section{REFERÊNCIAS BIBLIOGRÁFICAS}

ANVISA, Agencia Nacional de Vigilância Sanitária. Bulário Eletrônico. Disponível em:〈http://portal.anvisa.gov.br/bulario-eletronicor>Acesso em: I2 Set. 2020.

ANVISA, Agencia Nacional de Vigilância Sanitária. Coronavírus - Perguntas e respostas. Disponível em:<http://portal.anvisa.gov.br/coronavirus/faq > Acesso em: II Set. 2020.

ALBERT EINSTEIN. Manual Farmacêutico. 2020. Disponível em: <https://aplicacoes.einstein.br/manualfarmaceutico/Paginas/RelacaoMedicamentos.aspx? tipo $=\&$ filtro $=I \&$ busca $=\% 22 \% 22 \&$ itemID=IVERMECTINA $>$. Acesso em ro Set. 2020.

ALBERT EINSTEIN. Figura: Ação Antiviral da Ivermectina,. Disponível em: https://www.einstein.br/Documentos\%20Compartilhados/Visual-

abstract_\%2oIvermectina.pdf. Acesso em 29/10/2020

ANS. Agência Nacional de Saúde Suplementar. 2020. Disponível em: <http://www.ans.gov.br/aans/index.php?option=com_centraldeatendimento\&view = pergu nta\& resposta $=1696 \&$ historico $=19751570>$. Acesso em io Set. 2020.

ASCOM/ANVISA. Agencia Nacional de Vigilância Sanitária. Ivermectina e Nitazoxanida: volta a receita em uma via. Disponível em:<http://portal.anvisa.gov.br/coronavirus/noticias/-

/asset_publisher/3WSYdp5mIC2e/content/ivermectina-e-nitazoxanida-voltam-a-receitaem-umavia/21920I. Acesso em: il Set. 2020.

BARIFOUSE, R.; LEMOS, V. Ivermectina: o que a ciência diz sobre a "nova cloroquina". 2020. Disponível em: 〈https://www.bbc.com/portuguese/brasil-534948366734〉. Acesso em I2 Set. 2020.

BRAY, M. et al.Ivermectina e COVID-rg: Um relatório em Antiviral Research, amplo interesse, uma advertência da FDA, duas cartas ao editor $e$ as respostas dos autores.Antiviral Res . Junho de 2020; 178: 104805.

BRASIL. Ministério da Saúde - Secretaria de Ciência, Tecnologia, Inovação e Insumos Estratégicos em Saúde. Informe diário de evidências (COVID-19). 2020. Disponível em: <https://www.saude.gov.br/images/pdf/2020/August/o7/InformeDiario-referente-oI05.pdf $>$. Acesso em I2 Set. 2020. 
BRASIL. Ministério da Saúde (BR), Secretaria de Políticas de Saúde. Sobre a doença. Brasília (DF); 2020. Disponível em: <https://coronavirus.saude.gov.br/sobre-adoenca\#diagnostico>. Acesso em II Set. 2020.

BRASIL. Ministério da Saúde/SAPS, Protocolo de Manejo clínico do coronavírus (COVID-rg) na Atenção Primária à saúde. Brasília (DF); Maio de 2020. Disponível em: 〈https://portaldeboaspraticas.iff.fiocruz.br/wpcontent/uploads/2020/05/20200504_Protoco loManejo_verog.pdf $>$. Acesso em II Set. 2020.

CALY, L. et al O medicamento aprovado pela FDA ivermectina inibe a replicação do SARS-CoV-2 in vitro.Antiviral Res.Junho de 2020; 178: 104787. Disponível em: 〈https://www.sciencedirect.com/science/article/pii/Sor6635422030201I〉. Acesso em I2 Set. 2020.

DUARTE, D. B.; COElho, L. J.; NASCimento, G. N. L. Atualidades da farmacoterapia da COVID-19. 2020. Disponível em: 〈https://sistemas.uft.edu.br/periodicos/index.php/desafios/article/view/8983/16734〉.

Acesso em o9 Set. 2020.

FONSECA, J. J. S. Metodologia da pesquisa científica. Fortaleza: UEC, 2002. Apostila.

FUNDAÇÃO OSWALDO CRUZ. Novo coronavírus: protocolos do MS orientam profissionais de estados e municípios. Rio de Janeiro, 2020. Disponível em: <https://portal.fiocruz.br/noticia/novo-coronavirus-protocolos-do-ms-orientamprofissionais-de-estados-e-municipios $>$. Acesso em io Set. 2020.

GIL, A. C. Como elaborar projetos de pesquisa. 4. ed. São Paulo: Atlas, 2007.

GOVERNO DO ESTADO MATO GROSSO DO SUL/SECRETARIA DE ESTADO DE SAÚDE. Manual de condutas para enfrentamento do COVID-19. 2020. Disponível em: <https://www.saude.ms.gov.br/wp-content/uploads/2020/o3/Manual-de-Condutasvers\% $\mathrm{C}_{3}$

$\% \mathrm{~A}_{30-2}-25.03 .2020 . p d f>$. Acesso em I2 Set. 2020.

HENNIGEN, A. W. et al. TeleCondutas, Coronavírus (COVID-19): Informações para profissionais da APS. Versão 6. 2020. Disponível em: <https://atencaobasica.saude.rs.gov.br/upload/arquivos/202007/31130857-tc-coronavirus. pdf $>$. Acesso em o9 Set. 2020.

IVERMECTINA. [Bula].Vitamedic Indústria Farmacêutica Ltda. Medicamento genérico, Lei $\mathrm{n}^{\circ} 9.787$, de 1999.

IVERMECTINA.Fórmula Molecular. 
OPAS - Organização Pan-Americana da Saúde. Folha informativa COVID-ı́ Escritório da OPAS e da OMS no Brasil. Disponível em: $\langle$ https://www.paho.org/pt/covidı9>. Acesso em o8 Set. 2020.

OPAS - Organização Pan-Americana da Saúde. Recomendações sobre o uso de ivermectina no tratamento de COVID-rg. Disponível em: <https://iris.paho.org/bitstream/handle/ro665.2/52462/OPASIMSCDECOVIDi9200033_ por.pdf? sequence $=\mathrm{I} \&$ is Allowed $=\mathrm{y}>$. Acesso em II Set. 2020.

TESINI, B. L. Coronavírus e Síndromes respiratórias agudas (COVID-19, MERS e SARS).Universityof Rochester Schoolof Medicine andDentistry, 2020.Disponível em: https://www.msdmanuals.com/pt/profissional/doen\% $\mathrm{C}_{3} \% \mathrm{~A}$ 7asinfecciosas/v\% $\mathrm{C}_{3} \% \mathrm{ADrus}$-respirat $\% \mathrm{C}_{3} \% \mathrm{~B}_{3}$ rios/coronav $\% \mathrm{C}_{3} \% \mathrm{ADrus}$-es\% $\mathrm{C}_{3} \% \mathrm{ADndromes-respirat} \% \mathrm{C}_{3} \% \mathrm{~B}_{3}$ rias-agudas-covid-I9-mers-e-sars. Acesso em in Set. 2020.

TELESSAÚDERS-UFRGS. Existe algum tratamento específico para COVID-19.Rio Grande do Sul, 2020. Disponível em: 〈https://www.ufrgs.br/telessauders/posts_coronavirus/existe-algum-tratamentoespecifico-no-tratamento-da-infeccaoporcovidi9/\#: :text $=\mathrm{A}$ to $\mathrm{C}_{3} \% \mathrm{~A} 9 \% 200 \% 20$ momento\%20n\% $\mathrm{C}_{3}$ \%A30\%2oh\%C3\%Ai,COVID\%2Di9\%20\%C3\%A9\%20de\%2osuporte.>. Acesso em i2 Set. 2020.

TELESSAÚDERS-UFRGS. Qual a aplicabilidade dos testes diagnósticos para COVID19?. Rio Grande do Sul, 2020. Disponível em: https://www.ufrgs.br/telessauders/posts_coronavirus/qual-a-aplicabilidade-dostestesdiagnosticos-para-covid-19/. Acessoem I2 Set. 2020.

ZHANG, L.; LIU, Y. Potentialinterventions for móvel coronavirus in China: A systematic review. J. Med. Virol.92:479-490, 2020. 